\title{
Effects of changes in flow velocity on the phytobenthic biofilm below a small scale low head hydropower scheme
}

\author{
L. O'Keefe and S. Ilic \\ Lancaster Environment Centre, Lancaster University, Lancaster, UK
}

\begin{abstract}
This study presents a spatial analysis of physical and biotic river conditions below a low head hydro scheme in the River Goyt, UK. The overall aim was to assess whether changes in localized hydrological features, introduced by low head hydro, affect phytobenthic biomass. Single point and profile measurements of flow velocity and velocity vectors, elevation, depth and biofilm biomass were mapped. Results showed evidence of high flow velocity on the hydro side of the river and low flow velocity on the non-hydro side of the river. A number of distinct hydrological and morphological features were defined. Biofilm biomass appeared lower on the hydro side of the channel but no obvious relationship with flow velocity was observed. Future analysis will include evaluation of phytobenthic species on either side of the river channel and an investigation into the combined effects of a number of variables on phytobenthic biomass.
\end{abstract}

\section{INTRODUCTION}

In recent years (2009-2015) there has been renewed interest in hydropower in the UK (Demars and Britton, 2011; Robson et al., 2011, Anderson et al., 2014). This directly corresponds to renewable energy targets (Fraser et al., 2015), technology advances (Bracken and Lucas, 2011) and financial incentives (Fraser et al., 2015). Namely the UK's target to produce $15 \%$ of its energy from renewables by 2020 , new energy efficient turbines like the Archimedes Screw Turbine and the Feed in Tariff which provides payments to owners of renewable schemes based on the amount of electricity sold to the national grid (Fraser et al., 2015).

Current trends in hydropower applications suggest that the most popular schemes in England are low head designs where the height difference between the intake and outlet is less than 5 meters and where the turbine is situated directly on top of or directly adjacent to an existing weir (Fraser et al., 2015) 2015). The main focus of this paper is on low head hydro and from this point on the different layouts will be referred to as 'on weir' and 'by weir' schemes respectively. Figure 1 displays a schematic diagram of the two different layouts for 'on weir' hydro where the turbine is situated directly on top of a weir and 'by weir' where the turbine is situated directly adjacent to a weir.
Unfortunately understandings of the aquatic implications of low head hydro has not kept pace with the recent rise in the number of development proposals and even though it has been suggested that low head hydro is "environmentally benign" (Paish, 2002) there is a huge lack of evidence available to support this claim (Robson et al., 2011 and Anderson et al., 2014). There is an urgent need to conduct detailed investigations to develop current understandings (Robson et al., 2011).

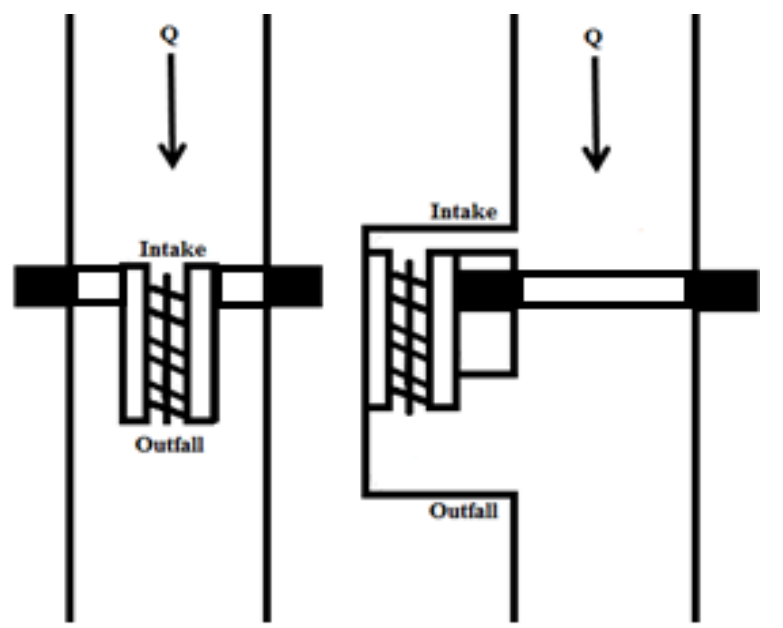

Figure 1. Schematic diagram of low head hydropower designs for 'on weir' and 'by weir' hydro respectively (adapted from EA, 2013) 
To date review studies have derived the potential implications from the relatively well known impacts of high head schemes. Conclusions are often based on expert opinion rather than experimental data and the impact of the weir alone is typically separated from the additional impacts of the scheme (Anderson et al., 2014). As schemes are often installed on existing weirs understanding the impacts of the weir on natural river conditions is crucial. The hydrological, morphological and biotic impacts of weirs are relatively well researched but the additional impacts or added benefits of the scheme are still uncertain.

Weir structures by their very nature can change natural river conditions. They can create a weir pond directly above the weir and a scour pool directly below the weir. This paper is concerned with the area directly below the weir where the cascading water erodes the river bed and banks. This area typically consists of a deep, wide pool with high energy, complex flow and a mid-channel island or tail riffle were the bed material is deposited as energy in the flow decreases (Mould et al., 2015). This area is often associated with specialized aquatic communities adapt to the complex environments. In line with the Environment Agency (Mould et al., 2015) this whole area will be referred to as the weir pool from herein.

Adding a scheme to a weir could cause changes in the weir pool environment. Robson et al., (2011) suggests that by changing the distribution of flow a scheme might cause changes in energy dissipation, flow pattern, morphology and aquatic communities. A modelling study conducted by the Environment Agency (Mould et al., 2015) supports this theory suggesting that there could be changes in the spatial variation of flow velocities and depths. Although they do conclude that such changes are unlikely to alter habitats.

A case study at Romney Weir on the River Thames revealed higher flow velocities along the river bank closest to the turbine and lower velocities on the opposite side of the river up to 20 meters beyond the structure (Mould et al., 2015). In this particular instance the Environment Agency (Mould et al., 2015) concluded that the changes in flow were not "ecologically significant" but such conclusions are based on expert opinion and species preference rather than observed evidence. In-situ biotic investigations need to be carried out before such claims can be accepted. Different communities could potentially develop either side of the river, especially sessile benthic communities, like the phytobenthos which are unable to move.

Particular changes in communities might occur were the flow from the main river channel and turbine outlet collides. There could be changes in hydrological and morphological features which in turn could alter biotic communities. Similarities can be drawn to the interface of two flows at river conflu- ences and tributaries. However this is most likely to occur at 'by weir' schemes where the flow is diverted through a turbine forebay, a small channel in which the turbine is situated. Where the water is discharged back into the main river channel and the two flows collide any of the following features could occur;

1 Stagnation at the upstream junction corner between the outlet and main channel,

2 Mixing, development of shear layers and scouring of benthic communities where the two flows combine, accelerate and scour the river bed,

3 Separated flow below the downstream outlet channel junction corner and bar formation,

4 Deflection where the flows collide and change path,

5 Advanced recovery downstream (adapted from Szupiany et al., 2009).

Further morphological changes could occur were the sediment that would have built up behind the weir will pass through the turbine forebay. This suggested by Anderson et al., (2014) and has been named the draw down effect.

This study will explore the potential aquatic implications of a low head 'by weir' schemes in a bid to improve knowledge and understandings, update and improve empirical evidence and to inform scheme designs to reduce their impact on the environment. The main motivation is to identify distinct hydrological, morphological and biotic features which could be attributed to the scheme.

\section{METHODS}

A two stage field campaign was designed in order to understand the hydrological, morphological and biotic features below a low head 'by weir' scheme. The first stage involved a spatial survey aimed at mapping single point measurements of flow velocity, bed elevation and phytobenthic biomass.

The phytobenthic community was chosen as a study species as it has many attributes which make it well suited to biomonitoring (Law, 2011). The phytobenthic community is easy to measure, collect, handle and store. Being sessile it is likely to change in response to changes created by the hydro scheme. Sitting at the base of the food web changes in its biomass will have far reaching effects on the rest of the food chain. High flow velocity and shear stress are often associated with scouring of the biofilm and reduced biomass. High flow velocity can roll cobbles and boulders and cause the phytobenthos to become detached (Law, 2011).

The second stage involved stationary Acoustic Doppler Current Profiler (ADCP) measurements and 
species analysis of samples collected from the near and far side hydro river banks. This paper presents results from the single point measurements and an initial analysis of the ADCP measurements.

\subsection{Study Site}

The field campaign was conducted in the River Goyt, UK, below Stockport Hydro (SJ936789441). Stockport Hydro was installed in 2011 and became operational in October 2012. The scheme is a low head 'by weir' scheme and consists of twin Archimedes Screw Turbines and a fish pass. The scheme has a "Hands Off Level" (HOF) of $6 \mathrm{~cm}$ which means that the scheme can divert $100 \%$ of the flow as long as $6 \mathrm{~cm}$ is maintained on the weir crest. Stockport Hydro monitors the abstraction rate of the scheme and records the level on the weir every 15 minutes. This data was utilized during the field campaign. It must be noted that only one turbine was operational during data collection. This turbine was closest to fish pass on the hydro-side river bank.

The site has a well-defined island in the middle of the river covered in vegetation and a number of permeable concrete structures on the far side river bank (non-hydro side). The concrete structures are represented by dashed lines in Figure 2. The concrete structures were not installed as part of the scheme.

Figure 2 shows the outline of the area surveyed. The turbines sit in the small channel adjacent to the main channel known as the turbine forebay. The outlet is the point where this channel meets the main river channel and were the water is discharged back into the main river. The flow from the weir flows down the channel towards the mid-channel island.

\subsection{Single point measurements}

The field campaign was split over two days in low flow conditions to cover as much as the localized areas as possible. On 24th August 2015 an extensive spatial survey was conducted over a 6 hour period. Figure 2 a) shows the points were near bed flow velocity (5cm from bed) was measured using a Valeport Electromagnetic Flow Meter (EMF), bed elevation was measured using a Trimble RTK GPS, depth was measured using a simple rigid meter rule and phytobenthic biomass was measured using the bbe moldeanke BenthoTorch an in-situ fluorometry device. Measurements were recorded in as many points as possible. Deep areas and areas surrounding concrete structures and large boulders were often difficult to measure meaning that some areas were not sampled. Following River Habitats Survey descriptors (Raven et al., 1998) a visual representation of habitats was sketched onto an aerial image of the site.

\subsection{Flow profile measurements}

On 10th September 2015 velocity profiles where measured at the near and far side river bank (hydro side and non-hydro side) using an Acoustic Doppler Current Profiler (ADCP) anchored in stationary positions for 5 minute time periods. Figure 2 b) is a schematic diagram of the points where the ADCP was anchored. An attempt was made to collect an even amount of profiles on the hydro and non-hydro side of the island. Measurement locations were often dictated by depth as the ADCP needs a minimum sampling depth of $20 \mathrm{~cm}$.

\subsection{Data analysis}

Spatial survey data including near bed flow velocities, bed elevation, depth and phytobenthic biomass was interpolated using kriging methods in Surfer Software. Habitat sketches were transferred from sketches to shape files in Surfer Software. Linear regression was used to explore the relationship between phytobenthic biomass and flow velocity.

ACDP measurements were averaged over depth and time and interpolated using kriging methods in Surfer Software. Velocity vectors were layered on top of the surface plot to display direction of flow. Surface plots were annotated to define and display distinct hydrological and morphological features.

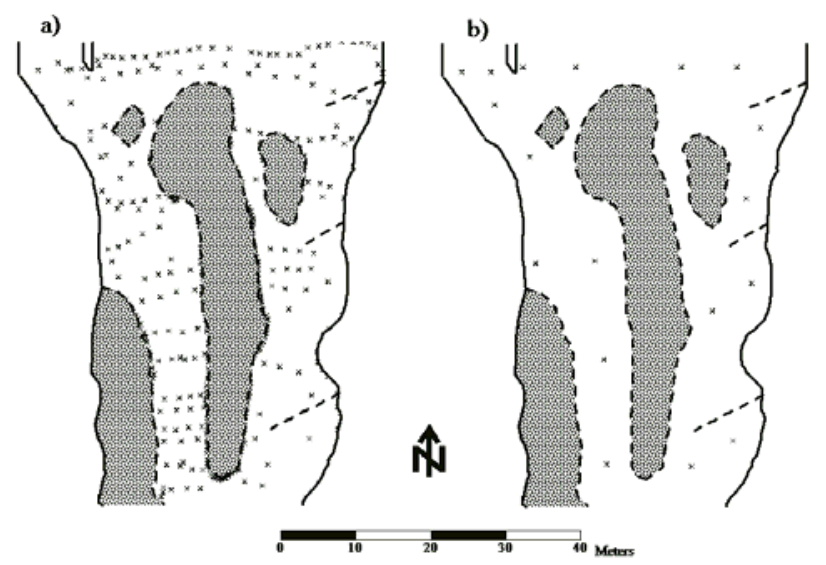

Figure 2. Survey design for assessing the aquatic implications of a low head 'by weir' hydro scheme on the River Goyt, UK (SJ936789441) were dashed lines represent concrete structures, crosses display the locations of measurements and diagrams a) and b) represent the spot point measurements and flow profile measurements respectively. 


\subsection{Single point measurements}

For the single point measurements the level on the weir remained at $6 \mathrm{~cm}$ and the abstraction rate was $1.11 \mathrm{~m}^{3} / \mathrm{s} \pm 0.02 \mathrm{~m}^{3} / \mathrm{s}$. The distribution of measured flow velocities is shown in Figure 3. Areas of high flow velocity are found between the hydro side deposit and the river bank, between the bank deposit and Mid-channel Island, and between the non-hydro side deposit and concrete structure (Figure 3). Lower velocities are typically recorded on the non-hydro side of the river (Figure 3) except velocities below the second concrete structure. Figure 4 shows the measured water depths clearly indicating zones of erosion and deposition.

Figure 5 shows phytobenthic biofilm biomass. Biomass appears lower on the hydro side of the river (Figure 5). Linear regression plots show downward trends in biofilm biomass as velocity increases (Figure 9) Low R-squared values do not support linear regression patterns.

Figure 6 shows the interpolated Ordinance Survey elevations where dashed lines represent deposits. The elevation plot shows distinct morphological features including erosion and deposition. The island has the highest elevation with measurements up to $54.7 \mathrm{~m}$. The bank deposit, hydro side and non-hydro side deposits have similar elevations. A pool from below the weir extends just above the island (Figure 6). An area of low elevation (high water depth) is evident in the turbine forebay.

Figure 7 displays habitat sketches from below Stockport Hydro. Distinct hydrological and morphological features are evident. A weir pool extends towards a glide on the non-hydro side of the river. An area of stagnation is visible at the upstream junction corner of the outlet. An area of separated flow is visible at the downstream junction corner of the outlet. There is an area of separated flow adjacent to the hydro side deposit at the point where the water from the outlet is discharged back into the main channel. A run extends from the outlet of the hydro scheme towards the end of the island. Riffles extend from the bank deposit on the hydro side of the river and from below the mid-channel island. Glides and pools form the majority of the area on the non-hydro side of the river. A run extends from the first concrete structure on the non-hydro side of the river, beyond the second concrete structure towards the island. Riffles are evident between both deposits on the hydro side and non-hydro-side of the river and the midchannel island.

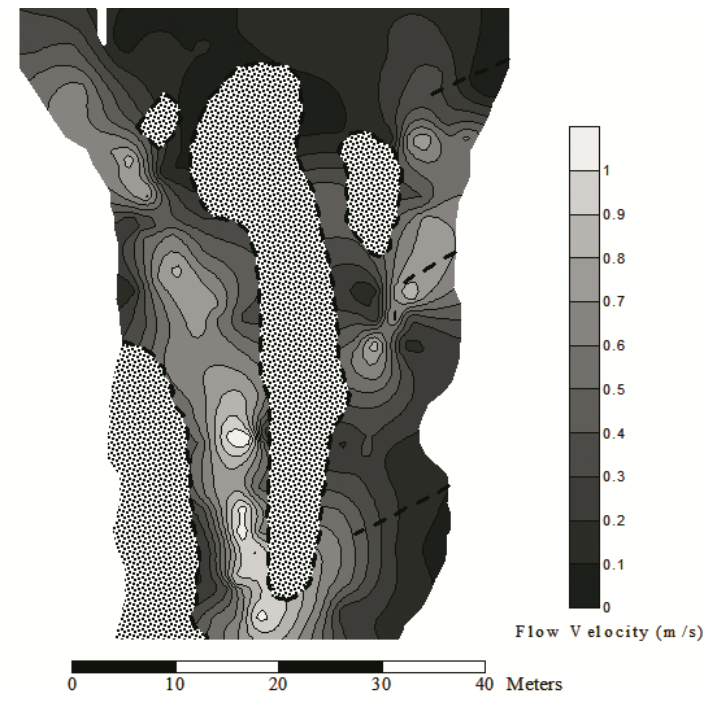

Figure 3. Interpolated plot of the single point flow velocity measurements below Stockport Hydro (SJ936789441).

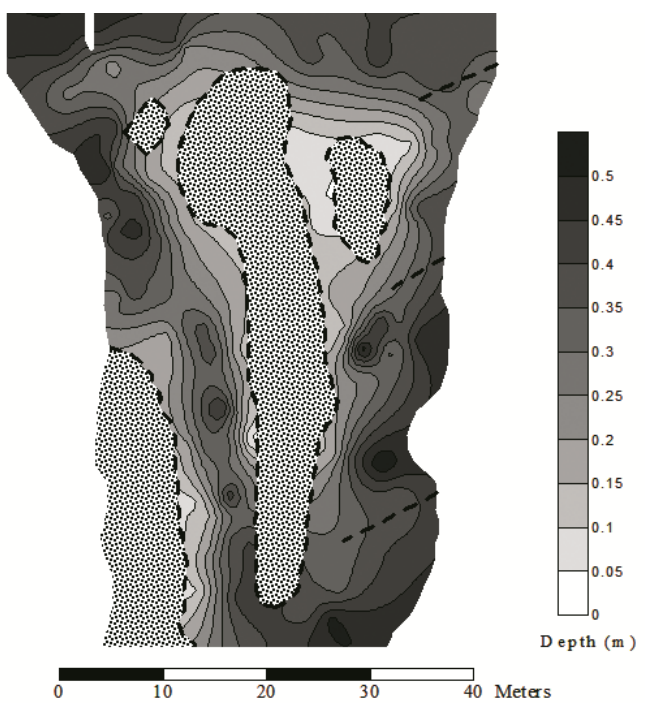

Figure 4. Interpolated plot of the single point depth measurements below Stockport Hydro (SJ936789441).

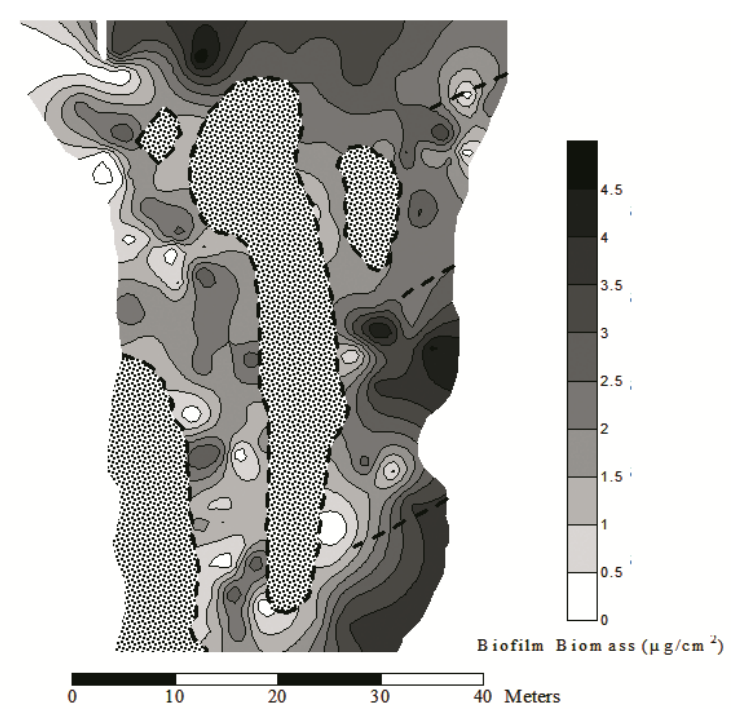

Figure 5. Interpolated plot of the single point biofilm biomass measurements below Stockport Hydro (SJ936789441). 


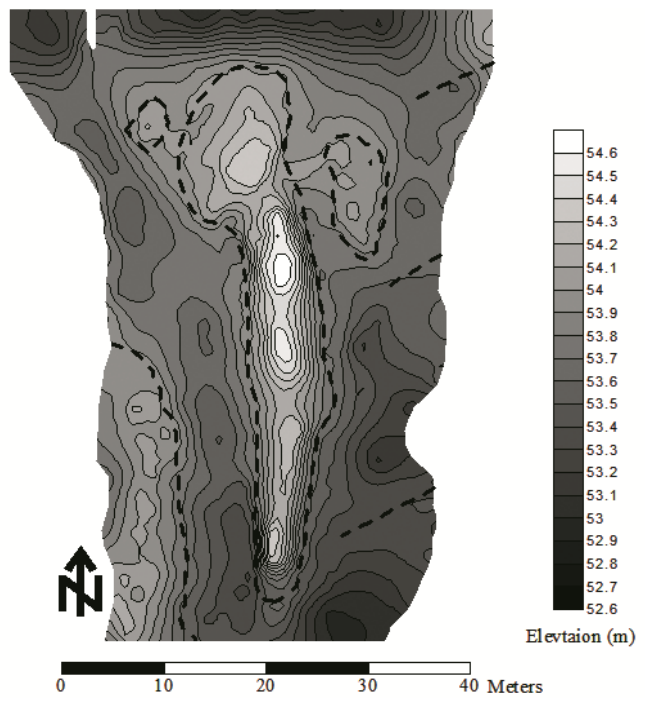

Figure 6. Interpolated plot of the single point elevation measurements below Stockport Hydro (SJ936789441).

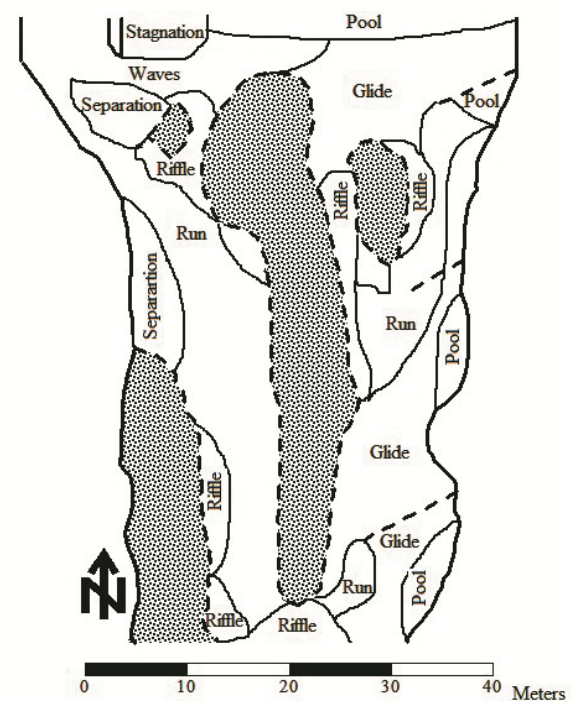

Figure 7. Habitat sketches from below Stockport Hydro (SJ936789441) based on RHS descriptors.

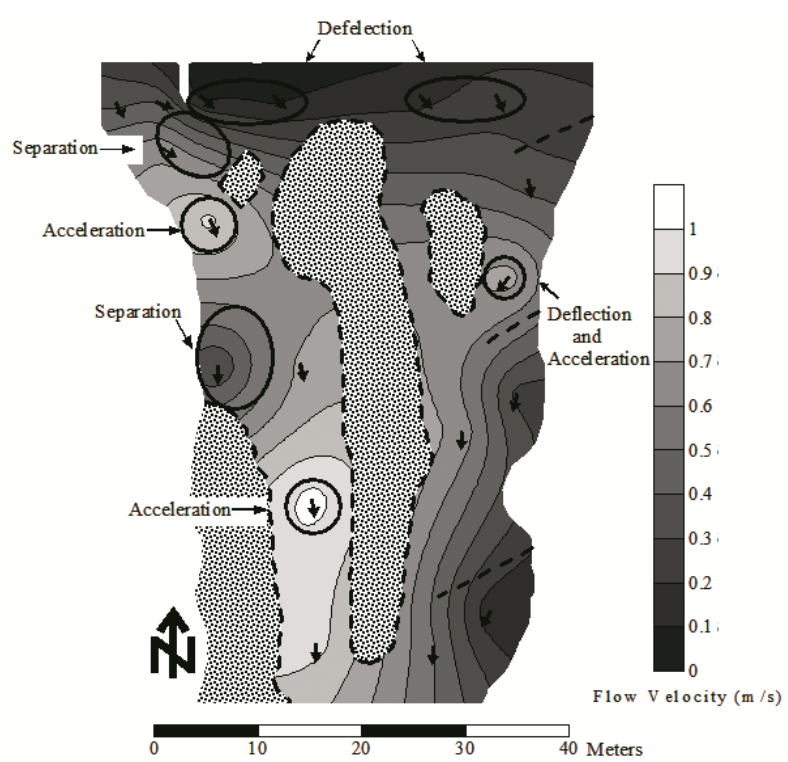

Figure 8. Annotated interpolated plot of measured flow velocity below Stockport Hydro (SJ936789441) using the ADCP.

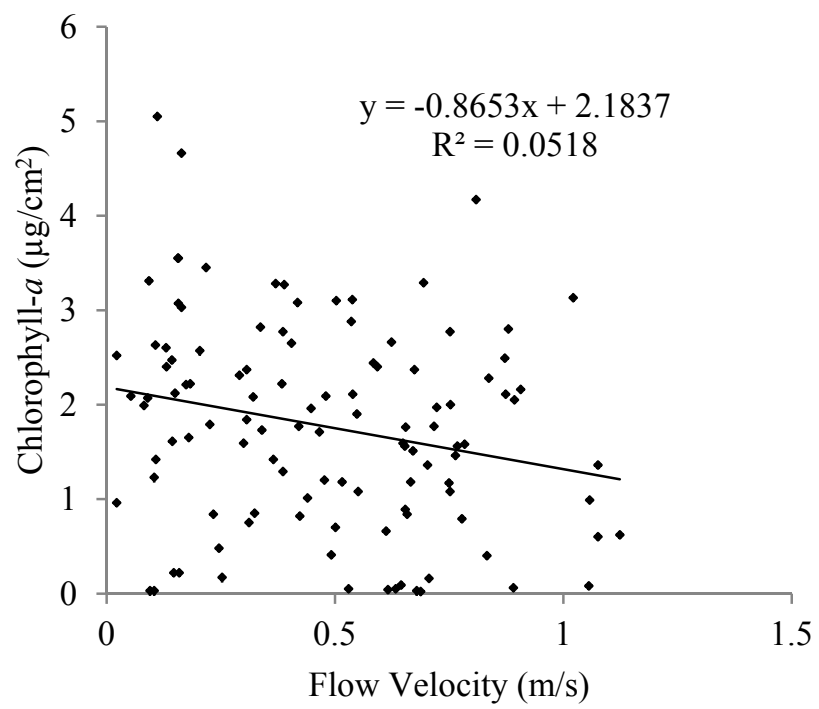

Figure 9. Correlation between single point flow velocity and biofilm biomass below Stockport Hydro (SJ936789441).

\subsection{Flow profile measurements}

For the flow profile measurements the level on the weir remained at $6 \mathrm{~cm}$ and the abstraction rate was $1.00 \mathrm{~m} 3 / \mathrm{s} \pm 0.03 \mathrm{~m} 3 / \mathrm{s}$. Interpolated plots reveal areas of distinct hydrological and morphological features Figure 8). Separation is evident between the outlets downstream junction corner and the bank deposit (Figure 8). Another area of separation is evident at adjacent to the hydro-side deposit extending into the outlet. Deflection is evident (Figure 8) where the two flows collide. Deflection is also recorded on the non-hydro side of the river on the opposite side of the mid-channel island. A bar was evident below an area of separation at the outlet. Acceleration occurred between the hydro side deposit and the bank and where the channel narrowed between the bank deposit and mid-channel island (Figure 8). Acceleration and deflection was evident between the nonhydro-side river bank and deposit. Lower velocities were visible on the non -hydro side of the channel compared to the hydro-side of the channel just as in single point measurements.

\section{DISCUSSION}

The measurements showed a difference between flow velocity and water depth, and to some level biofilm biomass on the hydro and non-hydro side of the river. High flow velocities towards the hydro bank supports the Environment Agencies (Mould et al., 2015) findings at Romney Weir in the River Thames were higher velocities were found on the hydro-side of the channel and lower velocities were 
recorded on the on the non-hydro side of the channel.

There is also clear evidence of distinct hydrological and morphological features typically attributed to the collision of two flows (Figure 3, Figure 7 and Figure 8). Habitat sketches display an area of stagnation at the upstream outlet junction corner (Figure 7). Stagnation is often recorded at the upstream junction corner at confluences (Szuipany et al., 2009) and as such is potentially related to the scheme.

Separated flow is evident at the point where the two flows collide. There is clear evidence of a deposit below this area of separation (Figure 3, Figure 7 and Figure 8). It is possible that this deposit is a result of sediment passing through the turbine channel from upstream. This would match the draw down theory presented by Anderson et al., (2014). As the flow separates and the velocity reduces in the separation zone the material is potentially deposited.

A second area of separated flow is evident at the downstream junction corner of the outlet (Figure 3, Figure 7 and Figure 8). This is another feature which is typically found were one channel meets another (Szuipany et al., 2009) and as such is potentially related to the flow discharging from the outlet. Below this area of separated flow is a bank deposit. Bank deposits are typically associated with the area of separation at confluence channels and as such could be related to the outlet of the hydro scheme.

Figure 8 shows deflection of flow in the main river channel at the point where the outlet discharges water. This deflection is likely to have been caused by the hydro scheme. This is a feature which is typically associated with the interface of two flows (Szuipany et al., 2009).

It must also been noted that the highest velocities are found at the points were the channel narrows (Figure 3 and Figure 8). There are areas of high velocity on both sides of the channel although the hydro side of the channel typically has the highest overall velocity. High velocities are evident between the hydro deposit and the river bank, the bank bar and the island and the non-hydro side deposit and concrete structure (Figure 3 and Figure 8). This is not surprising considering that acceleration is typically associated with channel narrowing.

The main morphological features, the scour pool and the mid channel island, are features typically associated with the aquatic environment below weirs. The water which cascades over the weir causes scouring of the river bed often creating a large scour pool (Mould et al., 2015). Were the energy in the flow is reduced the scoured material is often deposited forming an island or bar (Mould et al., 2015). This suggests that the scour pool and mid-channel island found below Stockport Hydro was a feature in the channel before the scheme was installed.

Figure 5 shows biofilm biomass below Stockport hydro. While there appears to be lower biomass on the hydro-side of the river, which in theory could be related to the scouring effect of the high flows from outlet (Law, 2011), there is no relationship between biofilm biomass and flow velocity (Figure 9). The phytobenthic biofilm can change according to a number of variables including depth, flow velocity, predation, light penetration, temperature and $\mathrm{pH}$ (Law, 2011). An investigation into the combined effects of a number of variables might yield better results and will be considered in future analysis. Equally analysis of communities' on the hydro and non-hydro side of the river will be carried out to determine if changes in flow distribution cause ecologically significant impacts.

\section{CONCLUSIONS}

Spatial surveys have been used to identify hydrological, morphological and biotic features below a low head 'by weir' hydro scheme. From the analysis of said features a number of points can be summarized;

1 Addition of a hydro scheme to a weir has the potential to change localized flow pattern and distribution.

2 The river channel below a low head hydro scheme is likely to consist of high flow velocities towards the hydro side of the river and low flow velocities on the non-hydro side of the river.

3 Distinct hydrological and morphological features associated with the collision of two flows are likely to be found below low head hydro 'by weir' schemes.

4 Changes in the distribution of flow could cause changes in phytobenthic biomass and community structure.

\section{ACKNOWLEDGEMENTS}

This work was fully supported by the Centre for Global Eco Innovation (CGE) and funded by the European Regional Development Fund (ERDF) whose support is gratefully acknowledged. Without the approval from Stockport Hydro and support from the volunteers this project would not have been successful. This help and support is greatly appreciated.

\section{REFERNCES}

Anderson, A., Moggridge, H., Warren, P. \& Shucksmith, J. 2014. The impacts of 'run-of-river' hydropower on the physical and ecological conditions of rivers. Water and Environment Journal 29 (2): 268-267.

Bracken, F.S.A \& Lucas, M.C. 2012. Potential impacts of small-scale hydroelectric power generation on downstream moving Lamprey. River Res. Applic. 29 (9): 1073-1081. 
Demars, B. O. L. \& Britton, A. 2011. Assessing the impacts of small scale hydroelectric schemes on rare bryophytes and lichens. Scottish Natural Heritage and Macaulay Land Use Institute Funded Report. Scottish Natural Heritage Commissioned Report No. 421. Available from http://www.snh.gov.uk/publications-data-andresearch/publications/search-the-catalogue/publicationdetail/?id=1731[accessed $18^{\text {th }}$ February 2016].

EA (2013). Guidance for run-of-the-river hydropower development. Environment Agency Report. [Online]. [Accessed 6th February 2015]. Available at: https:/www.gov.uk/government/uploads/system/uploads/at tachment_data/file/297147/LIT_4122_5f91bb.pdf

Fraser, D., Palmer, s. \& Stewart-Russon, I. 2015. Cumulative effects of hydropower on fish migration populations. Environment Agency Report - SC120078. Available from https:/www.gov.uk/government/publications/cumulativeeffects-of-hydropower-schemes-on-fish-migration-andpopulations [accessed 18th February 2016].

Mould, D., Whitmore, J., Bentley, S., Thomas, L. \& Moggridge, H. 2015. Assessment of the impact of hydropower on weir pool features. Environment Agency Report SC120077/R1. Available at https:/www.gov.uk/government/publications/hydropowerassessment-of-the-impact-on-weir-pool-habitats [accessed 18th February 2016].

Paish, O. 2002. Micro-Hydropower: Status and Prospects. Proc. Inst. of Mech. Eng. A J. Power Energy 216 (1): 31-40.

Raven, P.J., Holmes, N.T.H., Dawson, F.H., Fox, P.J.A., Everard, M., Fozzard, I.R. \& Rouen, K.J. 1998. River Habitat Quality the physical character of rivers and streams in the UK and Isle of Man. River Habitat Survey Report NO. 2. Available at http://www.riverhabitatsurvey.org/wpcontent/uploads/2012/07/RHS.pdf [accessed 17th February 2016].

Robson, A., Cowx, I. and Harvey, J. 2011. Impact of run of the river hydro schemes on fish populations. Scotland and Northern Ireland Forum for Environmental Research (SNIFFER). Available http://www.sniffer.org.uk/knowledge-hubs/resilientcatchments/water-framework-directive-and-uktag-coordination/impact-run-river-hydro-schemes-upon-fishpopulations/ [accessed $19^{\text {th }}$ February 2016].

Szupiany, R.N., Amsler, M.L., Parsons, D.R. \& Best, J.L. 2009. Morphology, flow structure, and suspended bed sediment transport at two large braid-bar confluences. Water Resources Research 45 (5). 